\title{
Self-generated power supply of agricultural enterprises based on renewable energy sources
}

\author{
Nikolay Rudenko ${ }^{1}$, Valery Ershov ${ }^{1, *}$, and Viacheslav Evstafev ${ }^{1,}$ \\ ${ }^{1}$ Don State Technical University, 1, sq. Gagarina, 344003, Rostov-on-Don, Russia
}

\begin{abstract}
The article contains the following technical proposals for the power supply of autonomous agricultural facilities using renewable energy sources: the use of hybrid solar-wind power plants, the use of vortex wind power plants with a vertical axis to use both the energy of horizontal wind flows and the energy of upward air flows. The structure and operation algorithm of an autonomous power supply system based on a hybrid solarwind power plant and a diesel generator for autonomous agricultural facilities of small and medium power in regions where there is no distribution electric network are proposed. This system will allow for insufficient wind load to ensure reliable power supply to an autonomous agricultural facility with minimal use of diesel fuel. The design of a vortex wind power installation has been developed. The fastening on the shaft of the wind power installation of a conical helical blade with a variable radius, decreasing in the direction from the lower to the upper cut of the socket, improves the efficiency of the installation. The proposed installation makes it possible to use small winds and low-potential thermal ascending air currents, reduce low-frequency vibration and noise, and also increase the stability and efficiency of use of wind energy.
\end{abstract}

\section{Introduction}

The Russian Federation pays a considerable attention to the development of energy. The goal of the state program is a reliable, high-quality and economically feasible provision of the needs of the country's domestic market for energy sources, energy and raw materials based on the principles of energy conservation and energy efficiency. The goal achievement will ensure reliable power supply to the facilities for various economic purposes, including agricultural enterprises, stable growth and strengthening of the state economy. However, the following features should be considered to realize this goal.

1. More than $65 \%$ of our country's territory represents the area of decentralized electric power supply. More than 20 million people live in this area (Fig. 1) [1].

2. Contemporary electric power supply of these territories is ensured mainly by diesel power plants. More than 900 diesel power plants of various capacities are operating at the moment in the Northern regions and the Far Eastern regions. They produce more than 2.5 billion $\mathrm{kWh}$ of electric power. Besides, diesel fuel in the amount exceeding 1 million ton is imported to these regions every year for providing them with fuel [1].

"Corresponding author: rnv.2017@mail.ru 
3. Taking into consideration that imported diesel fuel is expensive, the cost of producing $1 \mathrm{kWh}$ of electricity in these standalone decentralized regions ranges from 15 to 150 rubles per $1 \mathrm{kWh}[1]$.

4. Barrels out of diesel fuel, greenhouse gas and combustion product emissions greatly despoil the environment of the fragile nature of the North.

The use of renewable energy sources is one of the ways to solve the problem of reliable energy supply in the territories of self-generated and decentralized power supply, taking into account the need to create comfortable conditions for millions of people and environmental safety. Currently, hybrid solar-wind plants, which are a combination of solar panels with wind generators, are considered to be preferable [2]. Wind power engineering is developing the most intensively. Thus, the growth in construction of wind-driven power plants (WDPP) is about 30-35\% annually, and the current capacity of wind power stations in the world is more than 450 million kilowatts [2].

Therefore, elaboration of scientifically justified engineering proposals related to the use of WDPP for standalone power supply represent an urgent scientific and engineering objective.

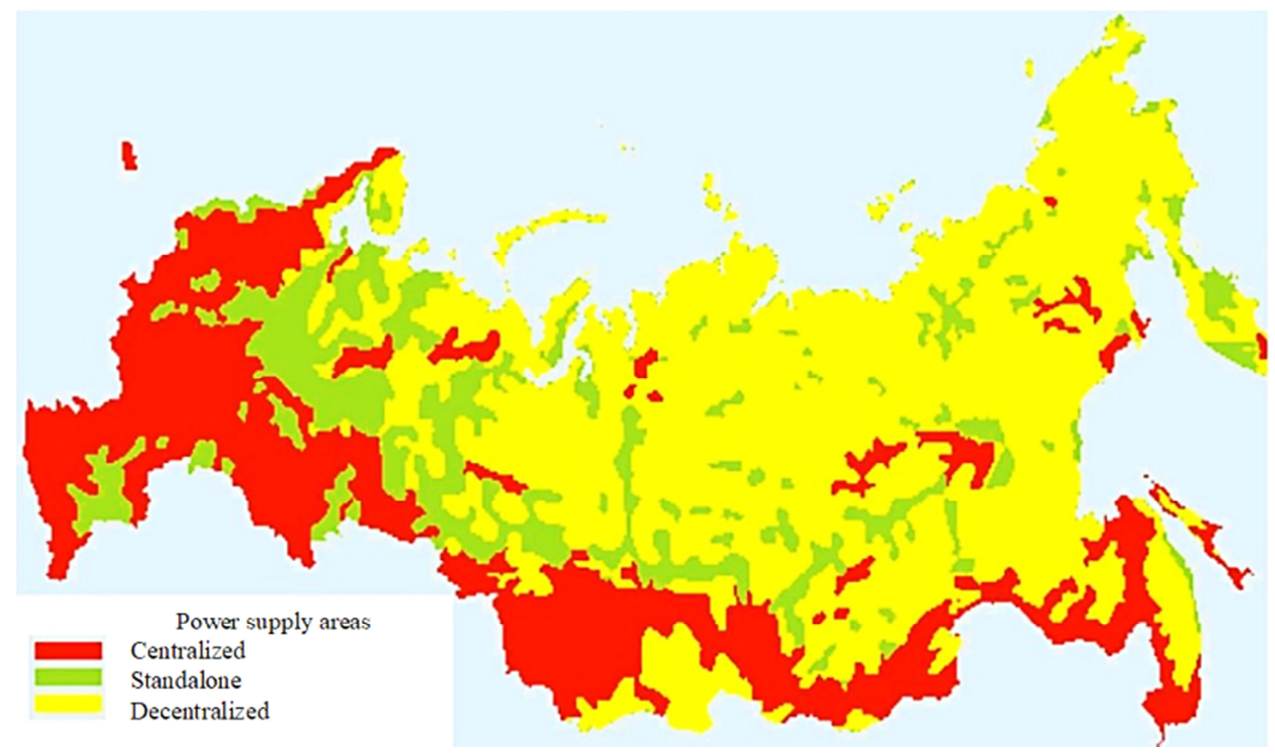

Fig. 1. Centralized, standalone and decentralized power supply areas.

\section{Research materials}

The problem is formulated as follows: to develop technical recommendations on the design of power supply system for the commercial farms based on renewable sources of electrical energy.

To solve this problem, it is necessary to study the following issues:

- analysis of the speed operation modes of modern wind-driven power plants (wind turbines, WDPP) and the determination of research areas;

- development of the structures of self-generated power supply system (SGPSS) for low- and medium-powered facilities, for example, small industrial and agricultural enterprises;

- proposal development for improvement of wind turbine WDPPs. 


\subsection{Analysis of speed operation modes at contemporary WDPP and selection of research areas}

Analysis of the world practice of operating the contemporary WDPPs with horizontal rotation axis enables to identify the following speed operation modes [2-4]:

- the use of WDPPs is not effective with an average annual wind velocity less than $4 \ldots 5$ $\mathrm{m} / \mathrm{s}$;

- most WDPPs start to produce useful power with an average annual wind velocity of $4 . .5 \mathrm{~m} /$;

- WDPPs are accelerated to the nominal mode with an average annual wind velocity of $5 \ldots 8 \mathrm{~m} / \mathrm{s}$;

- WDPPs operate in the mode of rated power and rotation velocity with an average annual wind velocity of $8 \ldots 11 \mathrm{~m} / \mathrm{s}$;

- WDPPs generate excess energy in relation to the rated power, and the rotation velocity may exceed the estimated one in the velocity range from $8 \ldots 11 \mathrm{~m} / \mathrm{s}$ to $23 \ldots 25 \mathrm{~m} / \mathrm{s}$;

- WDPPs are shut down at the velocities exceeding $23 \ldots .25 \mathrm{~m} / \mathrm{s}$ since the forces experienced by the wind wheel and the tower increase too much.

Based on the analysis of speed modes of WDPPs, it's possible to choose two basic study areas for improving the SPSS with WDPPs:

- improving the structure of the SGPSS with WDPPs for ensuring the required quality of generated electric power, reliable and uninterrupted electric power supply;

- improving the WDPPs themselves in the area of expanding the range of useful wind velocities (both smaller and higher velocities), as well as in the area of improving the energy conversion process for increasing the wind energy efficiency coefficient and increasing the time of WDPPs application during a year [4].

\subsection{Development of the structures of self-generated power supply system (SGPSS) for low- and medium-powered facilities}

For the country regions with undeveloped distributive networks infrastructure of a centralized energy system, a considerable distance from them or difficulties in connecting to stationary networks, the most suitable option for power supply for the created is the organization of power supply to the enterprise on the basis of autonomous power supply system (APSS) [4-6]. To solve the problems of ensuring not only the technological process of livestock production, but also ensuring the living conditions of production personnel as part of the power supply system, it is advisable to have at disposal the wind turbines (WT), solar cell batteries (SCB), storage battery (SB), and diesel-electric power plants (DEEP) as a backup. According to a number of technical characteristics, it is advisable to choose a unit with a vertical axis of rotation acting as a wind turbine of such an SGPSS [7-9]. The station diagram is shown in Fig. 2 [10-13]. 


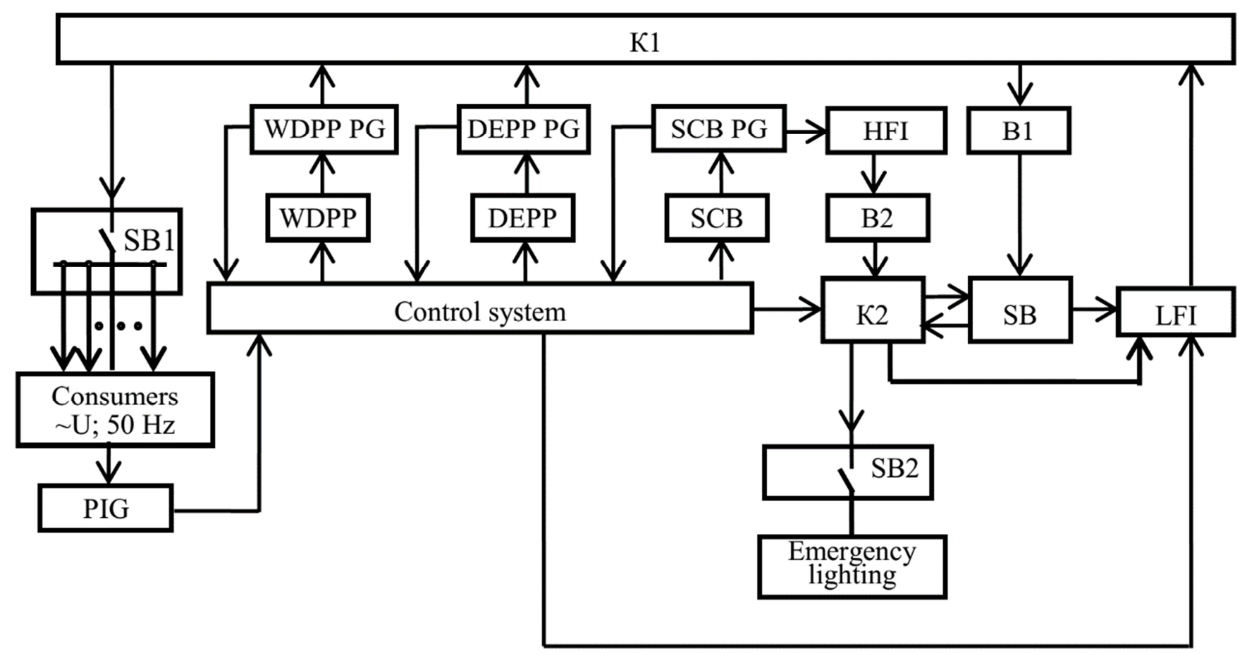

Fig. 2. Block diagram of standalone power supply system for a small farm based on the hybrid solarwind-driven power plant and diesel generator.

The basic principle of such SGPSS constructing consists in maximum possible application of wind and solar energy and minimum application of the energy produced by DEPP. It is advisable to estimate the wind energy through the current value of the electric power generated by the WDPP $\left(P_{\text {WDPP }}\right)$. Solar energy should be estimated through the current value of the electric power generated by the SCB $\left(P_{\mathrm{SCB}}\right)$. The total electrical power consumed at each moment can be evaluated by the required current value $\left(P_{\Sigma \text {.RCV }}\right)$.

The system operation algorithm is as follows. Depending on the specifics, the priority of the objectives to be solved by the station and the natural and climatic environment, the $\Sigma$ WDPP $\left(P_{\text {SET.WDPP }}\right)$ and SCB $\left(P_{\text {SET.SCB. }}\right.$. installed in its composition may be equal to or differ in nominal values in terms of power.

At the electric power current value of $P_{\text {WDPP }}$ greater than the current required value of $\left(P_{\Sigma . \mathrm{RCV}}\right)$, the station receivers can be fed from the WDPP. Similarly - under the current value of the electrical power of $P_{\mathrm{SCB}}$, all receivers can be fed from the SCB. In general, if the current values of the $P_{\mathrm{WDPP}}$ and $P_{\mathrm{SCB}}$ exceed the current value of the power $\left(P_{\Sigma \text {.RCV }}\right)$, level of the power generated by each of these sources is ensured by means of the appropriate controllers.

If the set powers are equal $\left(P_{\mathrm{SET} \cdot \mathrm{WDPP}}=P_{\mathrm{SET} \cdot \mathrm{SCB}}\right)$ the required power current value of $\left(P_{\Sigma . \mathrm{RCV}}\right)$ is provided through their combination by means of appropriate controllers as well. The current values of the generated powers are controlled by the corresponding gauges (WDPP PG, DEPP PG, SCB PG). The required current power value is controlled by the power input gauge (PIG).

In case when the total current value of $P_{\mathrm{WDPP}}$ and $P_{\mathrm{SCB}}$ is insufficient, it switches into operation and provides the DEPP station consumers. Thus, the DEPP is activated as a backup source only when it is impossible to provide the required current power of $P_{\square . \mathrm{RCV}}$ from WDPP and SCB. The described algorithm is implemented by the layout presented in fig. 2.

At a sufficient level of the current value of $P_{W D P P}$, the alternating voltage is fed to the station receivers and $\mathrm{B} 1$ rectifier from the WDPP output to recharge the SB through K1 interchanger Switch Board 1 (SB1).

At a sufficient level of $\mathrm{P}_{\mathrm{SCB}}$ current values, the DC voltage from the SCB output is supplied to the HF-inverter (HFI), from the output of which the voltage is supplied via the 
B2 rectifier, K2 interchanger to the LF-inverter (HFI) and further via the Switch Board 1 (SB1) to the station receivers. In case of lack of power produced separately by $P_{\mathrm{WDPP}}$ and $P_{\mathrm{SCB}}$, its shortfall is replenished by their jointly generated capacity. $\mathrm{K} 2$ interchanger, by the signals from control system, connects the accumulator battery (SB) to the $B 2$ rectifier (when the accumulator battery is charged from $\mathrm{SCB}$ ) or to the $\mathrm{B} 1$ rectifier (when the accumulator battery is charged from WLPP). In case of emergency situations, the storage battery (SB) provides operation of the emergency lighting system via K2 interchanger and Switch Board 2 (SB2).

In the event when the total current value of the electric power of the $P_{\mathrm{WDPP}}$ and $P_{\mathrm{SCB}}$ proves to be significantly lower than the necessary current value of $P_{\square . \mathrm{RCV}}$, the control system generates the command to disconnect all receivers from the WDPP and SCB via the K1 interchanger, launches the DEPP and switches the power supply to receivers from the WDPP and SCB to the DEPP via the K1 interchanger and the SB1 after monitoring its output parameters. SB is charged from the DEPP via $\mathrm{K} 1$ interchanger and $\mathrm{B} 1$ rectifier.

Thus, the proposed self-generated power supply system will ensure reliable power supply of the sustainable agricultural facility under the insufficient wind load. At the same time, the maximum possible use of wind and solar energy and the minimum use of diesel fuel are achieved.

\subsection{Elaboration of proposals for improving the WDPP}

It makes sense to consider proposals for improving the WDPP taking into consideration the wind energy potential distribution. In the most territory of Russia, it is within the range between 3 and $4.5 \mathrm{~m} / \mathrm{s}$. The use of WDPPs with a horizontal rotation axis is not effective with such types of wind, since their effective operation requires the average annual wind velocity exceeding $7 \mathrm{~m} / \mathrm{s}$. In Russia the zones of the coast and islands of the Arctic and Pacific oceans, the Azov-Black sea and Caspian zones are characterized by such wind energy potential, as can be seen in Fig. 3 [14]. Average annual wind velocities exceed $7 \mathrm{~m} / \mathrm{s}$ here. Wind velocity rarely reaches $4.5 \mathrm{~m} / \mathrm{s}$ in the rest of the territory, which does not ensure operating conditions for existing WDPPs. Therefore, new, more efficient WDPPs must be elaborated for using the energy of weak winds in the SGPSS composition.

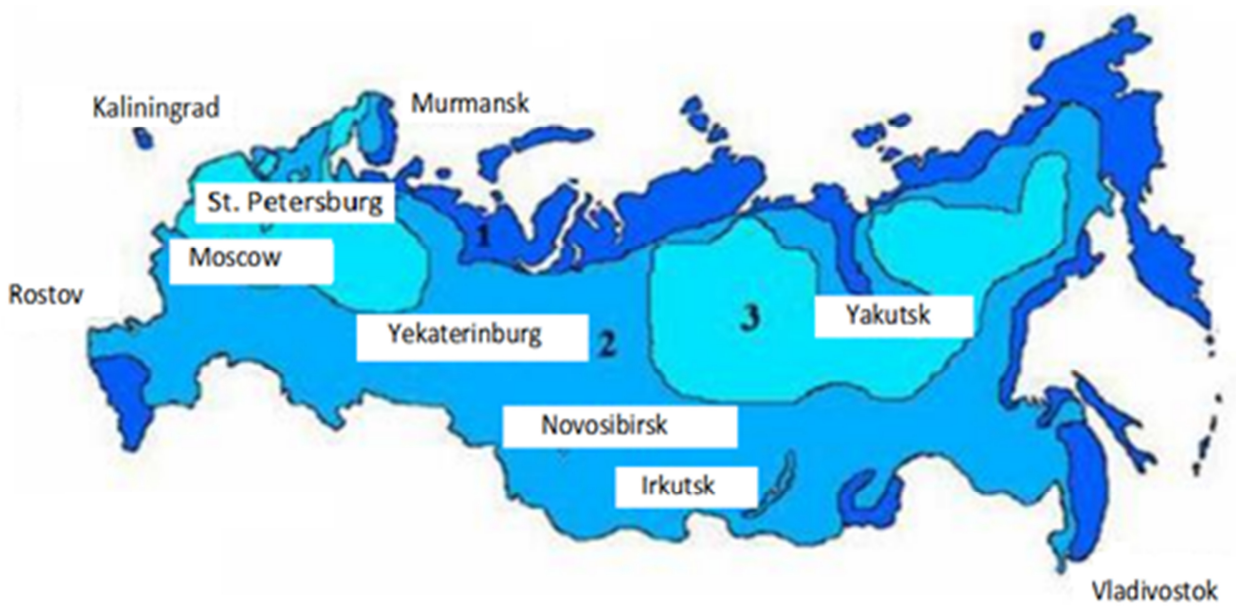

Fig. 3. Map of wind energy resources of Russia. The numbers indicate the zones with average annual wind velocities: 1 - above $6 \mathrm{~m} / \mathrm{s}$.; 2 - from 3.5 to $6 \mathrm{~m} / \mathrm{s}$.; 3 - up to $3.5 \mathrm{~m} / \mathrm{s}$., Source: http:// docplayer.ru/149544951-Proekt-vetroenergetika-novogo-pokoleniya.html. 
Taking into consideration the above approaches to constructing standalone power supply systems, the Don State Technical University (Rostov-on-Don) has elaborated the utility model of vortex WDPP [15], as well as invented vortex WDPP [16], which can be used in the SGPSS of standalone facilities in most of the territory of Russia, where the wind velocity is within $3-4.5 \mathrm{~m} / \mathrm{s}$. Proposed vortex WDPP is characterized by the following advantages [17-20]:

- low noise and vibration (less than $35 \mathrm{~dB}$ ), which enables to place it on roofs of the buildings related to industrial complexes, which makes it possible to use not only the energy of horizontal wind currents, but also the energy of vertical rising air currents during ventilation of the industrial building

- no necessity to construct a separate high-rise structure in the form of mast for WDPP with a height of at least 30 - 40 meters for ensuring the required wind velocity;

- fast speed and ease of installation, maintenance and repair, since the plant is located on the building roof at the plant base, instead of a high-rise mast;

- the possibility of using weak wind and low-potential thermal rising air currents enables to obtain reduced initial rotation velocity (from $1.3 \mathrm{~m} / \mathrm{s}$ );

- increased stability of all structures of the WDPP, since the generator and, consequently, the plant center of inertia are located at the WDPP base;

- simplification of operation technology through extending the service life of bearing assemblies.

Design of the WDPP invention is presented in Fig. 4 [16]. Wind-driven power plant comprises the flare fitting 5 made in the form of a truncated cone or cylinder that transits into a truncated cone, and a rotor located in it along its vertical axis, made in the form of shaft 2 with a conical screw blade 3 fastened on it. And the blades 7 are fixed by means of connecting disks 6 below it on the shaft 2 . The blades are partially protruded 8 from the lower part of the flare fitting 5 . The flare fitting 5 is mounted on the supports 9 with the axial bearings 14 (at least three in terms of stability conditions). The power crosspiece 4 which is rigidly connected to the flare fitting 5 is located at the level of the upper edge 16 of the flare fitting 5 in the horizontal plane. The center of this crosspiece contains the bearing assembly 1 which is fixed to the shaft 2 of the rotor with the possibility of rotation. The power crosspiece 11, the center of which contains the bearing assembly 13, in which the shaft 2 of the rotor is fixed with the possibility of rotation, is mounted at the level of the lower part of the supports 9 of the flare fitting 5 in the horizontal plane. The crosspiece 11 is rigidly connected to the supports 9 through the power elements of the structure 12 . The Electromotive Force generator 10 is mounted on the power crosspiece 11 at the lower parts of supports 9 of the flare fitting 5 in the horizontal plane. Rotor of the Electromotive Force generator 10 is rigidly connected to the shaft 2 of rotor. Dimensions of the rotor in the Electromotive Force generator 10 are conditioned by the possibility to generate the maximum possible EMF and are limited to the supports 9 of the flare fitting 5. Flare fitting 5 has a lower edge 15 . 


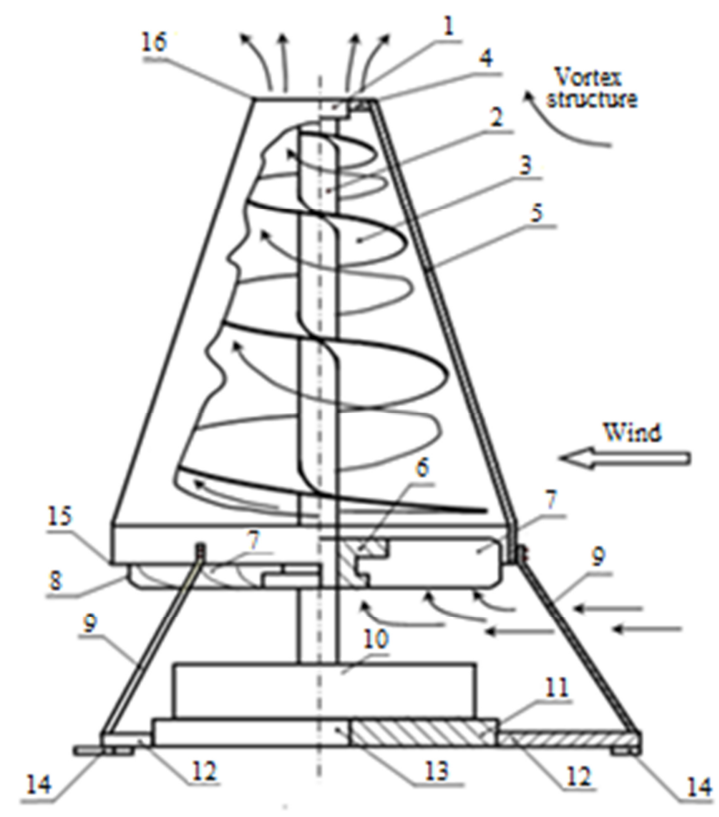

Fig. 4. Design of the vortex wind-driven power plant.

The essence of an invention is that the wind power plant containing a bell made in the form of a truncated cone or cylinder turning into a truncated cone, and a rotor located in it along its vertical axis, made in the form of a shaft with a conical screw blade fixed to it, and below it on the shaft blades are fixed by means of connecting disks with a partial protrusion of them from the lower part of the bell. The bell is mounted on at least three supports with thrust bearings, according to stability conditions, at the level of the upper cut of the bell in a horizontal plane there is a power crosspiece fixedly rigidly connected to the bell, in the center of which there is a bearing assembly, in which the rotor shaft is mounted rotatably. The EMF generator is mounted on the power crosspiece at the level of the lower part of the supports of the bell in a horizontal plane, the rotor of the EMF generator is rigidly connected to the rotor shaft, and the conical helical blade with a variable radius decreasing in the direction from the lower to the upper cut of the bell is fastened on the shaft inside the bell on the blades with partial protrusion of them from the lower part of the bell.

The process of the whole energy utilization of the vortex flow in the bell is as follows. With the beginning of the rotor rotation and the resulting air circulation in the direction from the lower to the upper cut of the bell, there is an increase of pressure on the conical screw blade.

The force of the wind flow $\bar{F}_{W F}$ due to the increase of pressure (Fig. 5) [16], is applied to the lower surface of the conical screw blade. At the point of application of force $\overline{\mathrm{F}}_{\mathrm{WF}}$ to the blade, two forces arise in it in a vertical plane. The first one is directed normal to the plane of the blade $\bar{F}_{N}$, and the second one is the tangential force $\bar{F}_{T}$ directed tangentially to the edge of the blade and in the direction coinciding with the direction of the edge of the conical screw blade. 


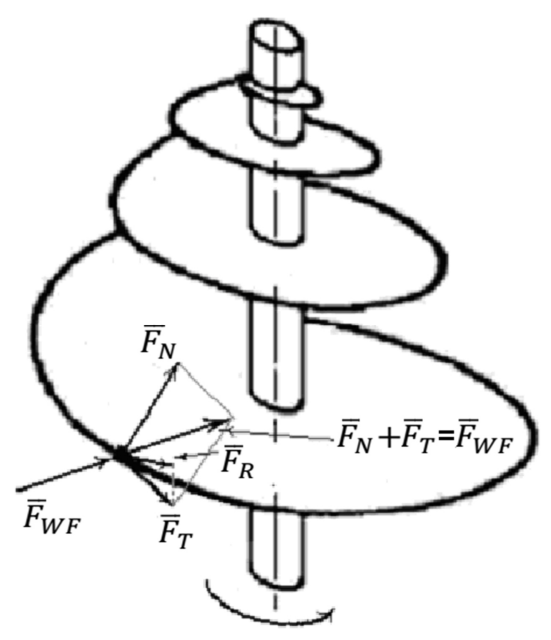

Fig. 5. Axonometric projection of a conical screw blade and the forces acting on it.

The resultant of these forces $\bar{F}_{N}$ and $\bar{F}_{T}$ representing the diagonal of the rectangle formed by these forces, as on the sides of the rectangle, is generated by the force of the wind flow $\bar{F}_{W F}$ and is equal to it in magnitude, i.e.

$$
\bar{F}_{N}+\bar{F}_{T}=\bar{F}_{W F}
$$

The projection of the force $\bar{F}_{T}$ onto a horizontal plane, that is perpendicular to the axis of rotation of the shaft of the wind turbine and that passes through the point of force application $\bar{F}_{W F}$, represents the rotation force $\bar{F}_{R \text {. }}$

Thus, as a result of the pressure of the vortex flow on the conical screw blade in the mouth, the work of the rotation force $\bar{F}_{R}$ occurs, which creates a useful capacity creep on the shaft of the wind power plant.

The improvement of the efficiency of wind energy usage can be shown as follows.

We can evaluate the components included in the equations characterized the balance of their power, assuming that the power of the wind flow $\mathrm{P}_{\mathrm{WF}}$, applied to the device of the patent [15] and to the proposed device are the same.

The power of the air flow applied to the device according to the patent [15]:

$$
P_{W F}=P_{B P P}+P_{U}+\Delta P_{L \cdot B P P}
$$

where $-P_{\mathrm{BPP}}$ is the power generated on the shaft by the blades with a partial protrusion of them from the lower part of the bell;

- $P_{\mathrm{U}}$ is the unused power of the vortex flow in the bell behind the blades with the partial protrusion of them from the lower part of the bell;

- $\Delta P_{\text {L.BPP }}$ is the power friction losses in bearings and friction of the air flow on the blades with partial protrusion of them from the lower part of the bell.

In the equation (1), the $P_{\mathrm{U}}$ component in relation to the proposed device is presented in the form:

$$
P_{N}=P_{C S B}+\Delta P_{L . C S B}+P_{U}^{\prime}
$$

where $-P_{\mathrm{CSB}}$ is the power created on the shaft by a conical screw blade; 
- $\Delta P_{\mathrm{L} . \mathrm{CSB}}$ is the power friction losses in bearings and friction of the air flow on a conical helical blade;

- $P_{\mathrm{U}}^{\prime}$ is the unused power of the vortex flow in the bell behind the conical screw blade.

The power of the air flow applied to the proposed device is next [16]:

$$
P_{W F}=P_{B P P}+\Delta P_{L . B P P}+P_{C S B}+\Delta P_{L . C S B}+P_{U}^{\prime}
$$

where $-P_{\mathrm{BPP}}$ is the power generated on the shaft by the blades with a partial protrusion of them from the lower part of the bell;

- $\Delta P_{\mathrm{L} . \mathrm{BPP}}$ is the power friction losses in bearings and friction of the air flow on the blades with partial protrusion of them from the lower part of the bell.

- $P_{\mathrm{CSB}}$ is the power created on the shaft by a conical screw blade which arises due to the use of vortex flow energy in the bell;

- $\Delta P_{\mathrm{L} . \mathrm{CSB}}$ is the power friction losses in bearings and friction of the air flow on a conical helical blade;

- $P_{\mathrm{U}}^{\prime}$ is the unused power of the vortex flow in the bell behind the conical screw blade.

It follows on the comparison of equations (1) and (3), that the unused power of the vortex flow $\mathrm{P}_{U}$ in equation (1) of the proposed device, as shown in equations (2), is the sum of the power generated on the shaft by a conical helical blade $P_{\mathrm{CSB}}$, power friction losses in bearings and friction of the air flow on a conical helical blade $\Delta P_{\mathrm{LCSB}}$ and the unused power of the vortex flow in the bell behind the conical screw blade $P^{\prime}{ }_{\mathrm{U}}$.

The unused power of the vortex flow in the bell in the proposed device is less than that in the patent, i.e. $P_{\mathrm{U}}^{\prime}$ is less than $P_{\mathrm{U}}$; and friction losses in both cases are comparable.

Then the efficiency of the devices for the patent and the present invention respectively, are [15]:

$$
\begin{gathered}
\eta_{1}=P_{\mathrm{BPP}} / P_{\mathrm{WF}} \\
\eta_{2}=\left(P_{\mathrm{BPP}}+P_{\mathrm{CBS}}\right) / P_{\mathrm{WF}}
\end{gathered}
$$

It follows on the equations (4) and (5), that the efficiency in the proposed device is higher.

Thus, fixing a conical helical blade with a variable radius on the shaft of the wind power plant, decreasing in the direction from the lower to the upper cut of the socket, allows to obtain an increase in power on the shaft due to the power created by the conical screw blade, which arises due to the use of the vortex flow energy in the socket, and on this basis, with the same value of the air flow power as in the prototype, to increase the efficiency in the proposed wind power installation.

\subsection{Operation of the vortex wind-driven power plant}

When the wind blows-off the protrusion of blades 7 of rotor, the shaft 2 of rotor starts to rotate, causing a difference in the velocities of the air layers in the space between the lower 15 and the upper 16 edges of the flare fitting 5 due to formation of a vortex current according to Bernoulli differential equation, thus causing generation of stable vortex air current which ensures conversion of wind energy into mechanical energy of rotation of the wind wheel containing the disks 6 and the blades 7 , and the shaft 2 of rotor.

The air current emerging in the flare fitting 5 affects the conical screw blade 3 . This action generates the force that acts on the conical screw blade 3 from the side of the air current flowing through it. The power which is generated by this force is proportional to the product of the mass momentum of the air passing through the conical screw blade 3 per 
time unit by the velocity difference before and after it. This force causes the emerging of additional torque which is generated by the conical screw blade 3 , ensuring an increase in the efficiency of wind energy utilization.

Thus, fixing the conical screw blade 3 with a variable radius which decreases in the direction from the lower 15 to the upper 16 edge of the flare fitting 5 on the wind-driven power plant shaft 2 enables to obtain capacity creep on the shaft 2 owing to the power generated by the conical screw blade 3 , which emerges owing to the use of vortex current energy in the flare fitting 5 , and on this basis - to increase the efficiency in the proposed wind-driven power plant with the same value of the air current power as in the prototype [16].

\section{Conclusions}

1. Based on the analysis of speed modes of the wind turbine, it is possible to choose two main areas of the research for improvement of SFE with wind turbines for sustainable agricultural facilities:

- improving the structure of the SGPSS with WDPP for ensuring the required quality of generated electric power, reliable and uninterrupted electric power supply;

- improving the WDPPs themselves in the area of expanding the range of used wind velocities (both to the smaller and higher sides), as well as in the area of improving the energy conversion process for increasing the wind energy efficiency coefficient.

2. The option of building the SGPSS based on a hybrid solar-wind-driven power plant and diesel generator for standalone facilities of small and medium capacity is elaborated. It's intended, for example, for cellular communication base stations, small industrial and agricultural enterprises, the regions where no distribution network is available and wind load is low.

3. A design of a vortex wind turbine is proposed for use as part of the SGPSS of sustainable agricultural facilities, which allows using small winds and low-potential thermal ascending flows, reducing low-frequency vibration and noise, placing it on the tops of industrial buildings, increasing the efficiency of using wind energy with ease of installation, maintenance and repair.

\section{References}

1. N.V. Rudenko, A.G. Sukiyazov, Yu.A. Shokova, 7th International Scientific Conference Science and Society (ISPC), 43-50 (2014)

2. REN21. Renewable Energy Policy Network or the 21-st Century. Renewables. Global Status Report 2004-2015

3. A. Bahaj, International Conference on Renewable Energy (2018) https://www.premc.org/doc/ICREN2018/ICREN2018_Book_Of_Abstracts.pdf

4. A. Hina Fathima, K. Palanisamy, Hybrid-Renewable Energy Systems in Microgrids (Woodhead Publishing Series in Energy, 2018) doi.org/10.1016/C2017-0-01772-X

5. A. Bose, International Conference on Renewable Energy (2018) https://www.premc.org/doc/ICREN2018/ICREN2018_Book_Of_Abstracts.pdf

6. M. Harper, International Conference on Renewable Energy (ICREN 2019), 24-26 (2019) https://www.premc.org/doc/ICREN2019/ICREN2019 
7. A. Kumar Yadav, H. Malik, M. Saad Bin Arif, Hybrid-Renewable Energy Systems in Microgrids (Woodhead Publishing Series in Energy, 2018) doi.org/10.1016/C2017-001772-X

8. P. Ganguly, A. Kalam, A. Zayegh, Hybrid-Renewable Energy Systems in Microgrids (Woodhead Publishing Series in Energy, 2018) doi.org/10.1016/C2017-0-01772-X

9. M. Ghofrani, N. Niromand Hosseini, Sustainable Energy - Technological Issues, Applications and Case Studies (2016)

10. A.F. Zobaa, S.N. Afifi, I. Pisica, IntechOpen, DOI: 10.5772/65971

11. N.V. Rudenko, V.V. Ershov, V.V. Evstafiev, IOP Conf. Series: Earthand Environmental Science 66(1) (2017)

12. V.K. Averyanov et al., Energy Conservation 6, 68-73 (2015)

13. N.V. Rudenko, V.V. Ershov, D.V. Trints, IOP Conf. Series: Earth and Environmental Science 403, 012123 (2019) doi:10.1088/1755-1315/403/1/012123

14. K. Shivarama Krishna, K. Sathish Kumar, Elsevier, 52(C), 907-916 (2015)

15. Next Generation Wind Power Project, DOCPLAYER Information Portal, https://docplayer.ru/149544951-Proekt-vetroenergetika-novogo-pokoleniya.html

16. N.V. Rudenko, V.V. Ershov, I.V. Pugachev, Device for converting kinetic wind energy into mechanical energy: utility model patent No. 182523 Russian Federation. No. 2018104927 Bull. Number 24 (2018)

17. N.V. Rudenko, V.V. Ershov, I.V. Pugachev, N.A. Konshina, Wind power plant: patent for invention No. 2689661 Russian Federation. No. 2018138330 Bull. Number 16 (2019)

18. R. Halstead, E. Solomin, Scientific Research Institute of Energy Structures 1, 36-41 (2010)

19. W.T. Chong et al., Journal of Central South University 19(3), 727-732 (2012)

20. Wind-Driven Generator in Heaven. Analytical Portal of the Chemical Industry, http://www.newchemistry.ru/letter.php?n_id=6249

21. N.V. Rudenko, V.V. Ershov, N.A. Konshina, IOP Conf. Series: Earth and Environmental Science 224(1) (2019) 